\begin{tabular}{ll}
\hline & $\begin{array}{l}\text { Kastamonu Eğitim Dergisi } \\
\text { Kastamonu Education Journal }\end{array}$ \\
$\begin{array}{l}\text { Mayıs } 2019 \text { Cilt:27 Sayı:3 } \\
\text { kefdergi.kastamonu.edu.tr }\end{array}$ & Başvuru Tarihi/Received: 17.01 .2018 \\
& Kabul Tarihi/Accepted: 26.07 .2018 \\
Dol: $10.24106 /$ kefdergi.2572
\end{tabular}

\title{
Eğitim Yöneticisi 21. yy. Becerileri Ölçeğinin Geliştirilmesi: Geçerlik ve Güvenirlik Çalışması ${ }^{1}$
}

\section{Developing on Educational Administrators' 21st Century Skills Scale: Study of Validity and Reliability}

\section{Öz}

\author{
Ömür ÇOBAN², Süheyla BOZKURT ${ }^{3}$, Adnan KAN ${ }^{4}$
}

Bu çalışmanın amacı, öğretmen algılarına göre eğitim yöneticilerinin 21. yy. becerilerine ne derece sahip olduklarını ortaya koymaya yönelik geçerli ve güvenilir bir ölçme aracı geliştirmektir. 21. yy becerileri alan yazında var olan sınıflamaya dayalı olarak belirlenmiştir. Taslak ölçeğin kapsam geçerliliğine uygun olup olmadığını tespit etmek için 6 uzmandan görüş alınmıştır. Araştırmaya Milli Eğitim Bakanlığında çalışan toplam 361 öğretmen katılmıştr. Toplanan verilerin alan yazına dayalı olarak belirlenen faktör yapısını doğrulayıp doğrulamadığını incelemek amacıyla Doğrulayıcı Faktör Analizi kullanılmıştır. Yapılan analizlerin sonucunda eğitim yöneticilerinin 21. yy. becerilerine ne derece sahip olduklarını ortaya koyan geçerli ve güvenilir bir ölçme aracı geliştirilmiştir.

Anahtar Kelimeler: 21.yy eğitim yöneticisi becerileri, okur-yazarlık becerileri, öğrenme ve yenilik becerileri, yaşam ve mesleki beceriler

\section{Abstract}

The aim of the study is to develop a valid and reliable scale for the assessment of the $21^{\text {st }}$ Century skills of educational administrators. $21^{\text {st }}$ Century skills is determined according to the classification in the literature. The content validity of the scale was obtained through the assessment of the items that were formed based on the literature by six experts. The study was carried out among 361 teachers working in schools. To achieve this aim, the $21^{\text {st }}$ Century skills of the educational administrators were tested via Confirmatory Factor Analysis. At the end of the study, a valid and reliable scale that can be used for assessing the skills of $21^{\text {st }}$ Century educational administrators was improved.

Keywords: educational administrators' 21st skills, learning and innovation skills, life and career skills, literacy skills

1. Bu çalışma, 31 Mayıs-3 Temmuz 2016 tarihinde Muğla Sıtkı Koçman Üniversitesi'nde yapılan International Eurasian Educational Research Kongresinde sözlü bildiri olarak sunulmuştur.

2. Karamanoğlu Mehmetbey Üniversitesi, Eğitim Fak., Eğitim Bilimleri Bölümü, Karaman, Türkiye, https://orcid.org/0000-0002-4702-4152

3. Çankırı Karatekin Üniversitesi, Edebiyat Fakültesi, Eğitim Bilimleri Bölümü, Çankırı, Türkiye, https://orcid.org/0000-0003-0330-4723

4. Gazi Üniversitesi, Eğitim Fakültesi, Eğitim Bilimleri Bölümü, Ankara, Türkiye, https://orcid.org/0000-0002-3610-0033

Atı / Citation: Çoban, Ö., Bozkurt, S., ve Kan,A. (2019). Eğitim yöneticisi 21. yy. becerileri ölçeğinin geliştirilmesi: Geçerlik ve güvenirlik çalışması.Kastamonu Education Journal, 27(3), 1059-1071. doi:10.24106/kefdergi.2572 


\section{Extended Summary}

Introduction. Organizations which compete in service economy and are in search of novelty need staff which can produce and create the information; are capable of team working; have effective communication skills; are well-educated; and have the capacity to solve complex problems in a flexible way (Partnership for 21st Century Skills, 2008). What's more, educational institutions have had to establish new regulations in order to provide the human resource that the $21^{\text {st }}$ Century economy entails. Accordingly, in educational institutions, new management models have been set up; the roles and responsibilities of the administrators have been redefined; and most importantly, alterations have been made in the curriculum (Bozkurt \& Aslanargun, 2015). While conventional educational models generally focus on subjects (mathematics, language, social science, science etc.); $21^{\text {st }}$ Century education emphasizes skills such as citizenship literacy, global awareness, financial literacy, heath literacy and environment literacy, along with conventional subjects through interdisciplinary approach (Pacific Policy Research Center, 2010).

Purpose. The aim of the study is to develop a valid and reliable scale for assessing of educational administrators' $21^{\text {st }}$ Century skills according to teachers' views.

Method. In this study, 361 teachers who work in private and public schools were reached. The scale draft, Educational Administrators' $21^{\text {st }}$ Century skills (EAS, 21cen.), consists of two parts. In the first part, there is demographic information as to the age, gender, educational status and the length of service of the participants. In the second part, there are 110 items as to 12 sub categories that can be collected under three main factors that can be listed as "Learning and Innovation Skills of $21^{\text {st }}$ Century Administrators", "Literacy Skills" and "Life and Profession Skills". To test the items whether they are convenient to assess the certain aspects in terms of their qualitative and quantitative sides, that is their content validity, the researchers consulted six experts who studied on management skills. The scale, which is based on teachers' points of view about to what extent educational administrators possess $21^{\text {st }}$ century skills, was prepared using five point Likert ( $1=$ Never, $5=$ Completely).

Data Analysis. The suitability of the sampling for the factor analysis was tested via Kaiser-Meyer-Olkin (KMO) and Bartlett Sphericity in this study that focuses on developing a scale for assessing educational administrators' $21^{\text {st }}$ Century skills. In the analysis, KMO value was .986 and Bartlett value was $43626,274(p=.000)$. Besides this, the normal distribution of the collected data was analysed with scatters diagrams and descriptive statics. The average of the collected data was 3.46, the median of the data was 3.51, and the coefficient of skewness was .400 and the coefficient of kurtosis was .293. In order to examine whether the collected data verified the factorial structure based on the literature, Confirmatory Factor Analysis (CFA) was analysed using Lisrel 8.8. Programme. The margin of error was .05. In this study, second order CFA was used.

Findings. As a result of the CFA analysis conducted to examine the factor structure of the EAS, $21^{\text {st }}$ Century Scale, fourteen items (S8, S14, S15, S40, S44, S47, S50, S54, S63, S69, S84, S86, S94, S101) with a standardised factor loading above 1.00 were removed from the model, and then the new model was built. In this study, the value was 2.22, and according to the value and the literature, it can be said that factor structure has a perfect fit. When the other fix indices were examined, RMSEA value was found to be .07 and SRMR was found to be .032 . It can be observed that SRMR value is 0.032 . The fit indices of the model show that the values in this model are very close to perfect fit. The factor loadings change between 0.72 and 0.99 . When the factor loadings of each item are examined, it can be said that every item has a good level of relationship with the related factor. $t$-values related to the explanation of latent variables with observable variables are between 11.06 and 13.11. $R^{2}$ values are between the values, 0.42 and 0.79 ; and these values are acceptable values. As a result, it can be said that the scale is valid with an acceptable level.

To examine both the reliability of EAS, $21^{\text {st }}$ cent. Scale and its subcategories, Cronbach Alpha, Spearman Brown and Guttmann internal consistency coefficients were calculated. Cronbach Alpha, Spearman Brown and Guttmann internal consistency coefficients of EAS, $21^{\text {st }}$ Century Scale were respectively $.99, .98$ and .98 . The Cronbach Alpha coefficients of the subcategories vary between .90 and .96; Spearman Brown coefficients of them vary between .89 and .95; and Guttmann coefficients vary between .86 and .94. Each factor has a significant relationship with both the other subfactors and the overall scale. The correlation values of cross factor were all positive and at a high level. Moreover, correlation values that were generated from general scale points of the factors were also positive and at a high level. On the basis of these findings, it can be said that factors have a positively high relationship with the scale and that the internal consistency of the scale was high.

Conclusions and Recommendations. In this study, validity and reliability of EAS, $21^{\text {st }}$ Century Scale, which was developed to assess to what extent educational administrators have $21^{\text {st }}$ Century Skills according to teachers' points of view, was explored. It was observed that Cronbach Alpha reliability of EAS, $21^{\text {st }}$ Century Scale was high not only on the basis of factors but also on the basis of the scale in general. The correlation among the factors, and between the factors and the general scale total points were also found to be positively high and significant. These results can be seen as hints for the reliability of the scale. CFA analysis was used in order to test the construct validity of the EAS, $21^{\text {st }}$ cent. It was seen that the standardised factor loadings of the scale were at a high level and t-values were significant. 


\section{Giriş}

Günümüzde üretim temelli ekonomi, yerini bilgi ve yenileşmenin ön plana çıktı̆ı hizmet ekonomisine bırakmıştır. Hizmet ekonomisinde rekabet eden ve yenilik arayışında olan örgütler, bilgiyi üretebilen ve yönetebilen, takım çalışması yapabilen, etkili iletişim becerisi olan, karmaşık problemlere esnek cevap verebilme yeteneğine sahip, daha iyi eğitilmiş çalışanlara intiyaç duymaktadır (Partnership for 21st Century Skills, 2008). Eğitim kurumları da, 21. yüzyıl ekonomisinin intiyaç duyduğu insan kaynağını sağlamak için, kendi bünyesinde düzenlemeler yapmak zorunda kalmıştrr. Bu doğrultuda, eğitim kurumlarında yeni yönetim modelleri oluşturulmuş, okul müdürlerinin görev rol ve sorumlulukları yeniden tanımlanmış ve her şeyden önemlisi eğitim programlarında değişikliğe gidilmiştir (Bozkurt \& Aslanargun, 2015). Geleneksel eğitim modelleri genellikle konu alanlarına (matematik, dil öğrenimi, sosyal bilimler, fen bilimleri vb.) odaklanırken; 21. yy. eğitimi, disiplinler arası yaklaşımla geleneksel konu alanları ile birlikte vatandaşlık okuryazarlığı, küresel farkındalık, finansal okuryazarlık, sağlık okuryazarlığı ve çevre okuryazarlığı gibi becerileri ele almaktadır(Pacific Policy Research Center, 2010).

Alan yazında, eğitim yöneticilerinin becerilerini sınıflamaya yönelik çalışmalara ilk, 1955 yılında Robert Katz'ın, yönetsel beceriler "conceptial skills", insani ilişki becerileri "human relation skills" ve mesleki ve teknik beceriler "technical skills" boyutlarını içeren çalışması ile başlanmıştır. Günümüzde yönetici becerileri genellikle bu sınıflama ile dile getirilmektedir (Ağaoğlu, Altınkurt, Yılmaz, \& Karaköse, 2012). Ancak teknolojinin gelişmesi, küreselleşme, dünya ekonomisinin ihtiyaç duyduğu insan tipinin değişmesi gibi nedenlerle birçok örgüt, eğitim sistemlerini ve öğretim programlarını geliştirmek için farkı çerçeveler geliştirmiştir (Silva, 2008). "Yüksek seviye becerileri” ya da sıklıkla kullanılan adıyla "21. Yüzyıl Becerileri, problem çözme, yaratıılık ve inovasyon, eleştirel düşünme, iletişim ve işbirliği, okuryazarlık (medya, ICT vb.), esneklik ve uyum sağlayabilme, girişimcilik ve öz yönlendirme, üretkenlik ve hesap verebilirlik, liderlik ve sorumluluk gibi becerileri içermektedir (Partnership, 2011). Bu bağlamda bu çalışmanın amacı alan yazında sınıflanan bu becerilere, eğitim yöneticilerinin ne derece sahip olduklarını belirlemeye yönelik, öğretmen algılarına göre geçerli ve güvenilir bir ölçme aracı geliştirmektir.

\section{Kavramsal çerçeve}

Eğitim yönetimi araştırmalarında genellikle "beceri" (skill) ve "yeterlilik" (competence) kavramları birbirlerinin yerine kullanılsa bile iki kavram arasında temel bazı farklılıklar bulunmaktadır. Türk Dil Kurumu sözlüğüne göre beceri, elinden iş gelme durumu, ustalık, maharet; kişinin yatkınlık ve öğrenime bağlı olarak bir işi başarma ve bir işlemi amaca uygun olarak sonuçlandırma yeteneği diye tanımlanırken; yeterlik, bir işi yapma gücünü sağlayan özel bilgi, kifayet, ehliyet şeklinde tanımlanmıştır(Türk Dil Kurumu , 2015). Webster'ın sözlüğünde ise beceri, bir görevi veya işi tamamlamak için kullanılan yöntem ve aracı kullanabilme bilgisi veya bir işte veya performansta kişinin bilgisini etkili olarak kullanabilme yetisi olarak tanımlanırken; yeterlilik, yaşama uyum sağlamak ve yaşamın gerekliliklerini yerine getirmek için gerekli yeterli özellik; belli bir görev için yeterli bilgi, yargı, beceri veya güce sahip olabilme şeklinde tanımlanmaktadır(Webster, 2016). Bu tanımlardan da anlaşılacağı gibi, yeterlik, bir işin üstesinden gelmede asgari bir temel oluştururken; beceri, ustalık ve maharet gerektirmektedir. Bu çalışmanın amacl; eğitim yöneticisi yeterliklerini belirlemek olmadığından geliştirilecek ölçekte de yeterlik yerine beceri kavramı kullanılacaktır. Nitekim, ölçeğin temelini oluşturan "21.yy Öğrenme Çerçevesi"nde de beceri kavramı kullanılmıştır.

\section{1. yy Öğrenme Çerçevesi}

2010'lu yılların başında, başta Amerika Birleşik Devletleri olmak üzere aralarında American Association of School Librarians, National Education Association gibi derneklerin ve Lego, Microsoft, Pearson, ETS, İntel, HP, Dell, Apple, Crayola, Cisco gibi eğitim ile ilgili şirketlerin de bulunduğu 32 üyeli bir "21 Yüzyıl Becerileri" ortak çalışma grubu tarafindan detaylı bir çalışma sonucu etraflı bir "21. Yüzyıl Öğrenme Çerçevesi" geliştirilmiştir(Department of Defense Education Activity-DODEA-, 2014). Şekil 1'de görüldüğü gibi, bu çerçevede 21. yy becerilerine ait öğrenme ve yenilik becerileri, yaşam ve mesleki beceriler, okuryazarlık (bilgi ve medya) becerileri olmak üzere üç ana tema ve her bir ana temanın altında farklı beceri grupları oluşturulmuştur (Partnership for 21st Century Skills, 2008). 


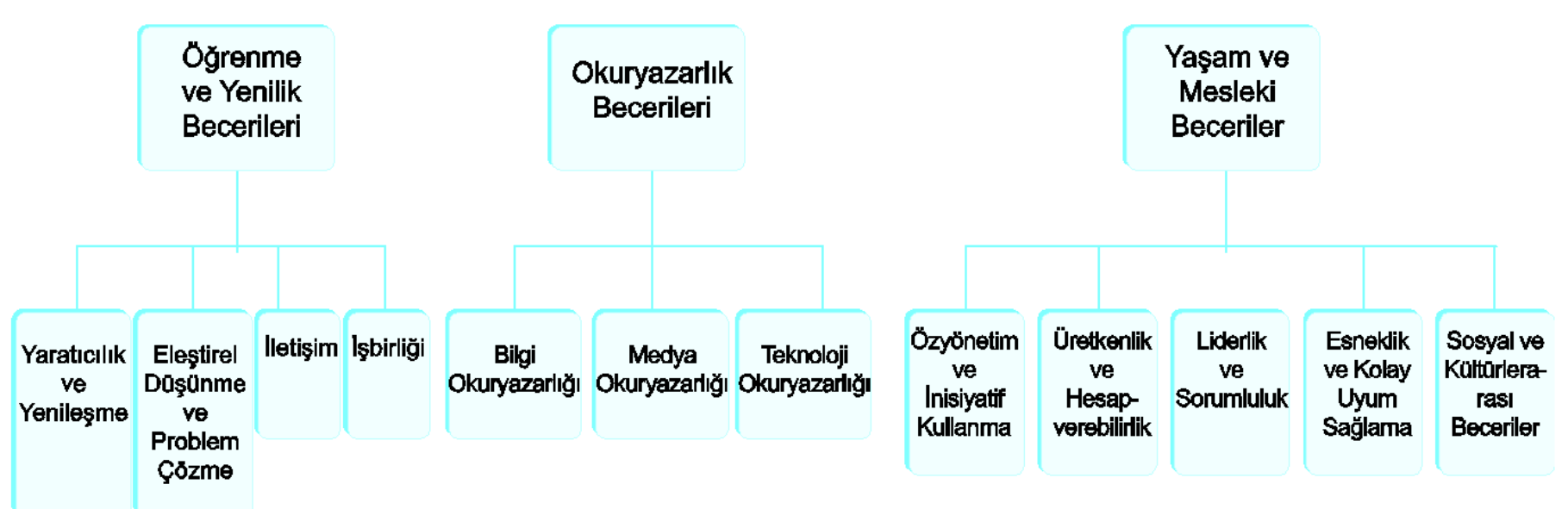

Şekil 1. 21. yy. becerileri

Öğrenme ve Yenilik Becerileri

Yaratıcılık (Cretaivity) ve Yenileşme (Innovation) :Yaratıcılık, kısaca farklı bakış açıları ile kurum içinde yaşanan sorunlardan, bilgi eksikliklerinden ve uyumsuzluklardan yola çıkarak kurum için somut ve yararlı katkı sağlayabilecek yeni fikirler üretmek olarak tanımlanabilir (Sungur, 1997; Torrance \& Ball, 1974). Yenileşme ise; yaşanan sorunlar, bilgi eksiklikleri gibi uyumsuzluk ve problemlerden yola çıkarak değil, genel anlamda yeni fikirler geliştirmektir. Başka bir deyişle, bir ürün veya hizmeti daha güzel, daha kullanışlı ve daha çok insanın işine yarayacak hale getirme sürecidir (EBA, 2016).

Yaratıcı düşünmek için; fikir oluşturma tekniklerini (beyin firtnnası gibi) geniş bir yelpazede kullanmak; marjinal ve radikal kavramları da göz önünde bulundurarak yeni ve değerli bilgileri oluşturmak ve kurum çalışanlarının kendi fikirlerini değerlendirmelerini, analiz etmelerini ve detaylandırmalarını sağlamak gerekir. Bunun için de eğitim yöneticisinin farklı bakış açılarına duyarlı olması, yeni fikirlerin gerçek dünyaya nasıl adapte olabileceğini anlaması ve çalışmalarda özgünlük ve yaratıcılığa sınır koyulmaması gerekir. Yenilikleri uygulamak için ise; üretilen bilgi veya ürünleri, somut ve yararlı bir katkı sağlayacak şekilde korkmadan ve büyük bir cesaretle alanda kullanılması gerekir (Partnership of 21st Century Skills, 2016).

Eleştirel Düşünme ve Problem Çözme: Eleştirel düşünme, kişinin düşünce sisteminde oluşturduğu yapıları iyi tanıması ve bu sistemi iyi yöneterek entelektüel düzeydeki standartlara uygun düşünme becerisi ortaya koyma sürecidir (Cottrell, 2005; Demirel, 1999). Problem çözme ise, bir problem veya sorunla karşılaşan bireyin, problemin boyutlarını detaylı bir şekilde irdelemesi ve boyutlar arasındaki ilişki örüntülerini analiz ederek farklı çıkış yolları bulabilmesi sürecidir (Bringham, 1998; Sungur, 1997).

Bu tanımlardan yola çıkarak eğitim yöneticilerinin kurumda karmaşık durumlarda doğru seçim yapıp karar vermesi, kurum içerisinde yaşanan sorunlara ilişkin farklı değişkenler arasındaki ilişkileri anlaması, farklı çözüm yollarını görebilmesi ve en doğru çözümleri bulabilmek için doğru sorular sorması, sorunları çözebilmek için analiz ve sentez yapabilmesi gerekmektedir. Bunları yapabilmesi için de intiyaç duyacağı beceriler şu şekildedir (Cottrell, 2005; Partnership for 21st Century Skills, 2008): a)Problemin nedenini muhakeme yeteneğini (tümden gelim, tümevarım vb.) kullanarak sorgulama yapmak, b)Karmaşık sistemlerde genel sonuçlar üretmek için bütünün birbirleriyle etkileşim halinde olan parçalarının birbirlerini nasıl etkilediğini analiz etmek, c)Kritik sorular sorabilmek, d)Çözüm alternatifleri konusunda karar verebilmek, e)inançları, iddiaları ve kanıtları değerlendirerek etkili bir şekilde analiz yapmak, f)Alternatif görüş açılarını analiz etmek ve değerlendirmek, g)Bilgi ve yorumlar arasında ilişkiler kurarak sentezlemek, h)Analize dayalı en iyi sonuçları görsel olarak çizmek ve bilgiyi yorumlamak, ı)Öğrenme deneyimleri ve süreçleri üzerine eleştirel bir bakış açısı yansıtmak, i)Kararlar ve işlemler konusunda eleştirilerini yansıtmak, j)Daha önce karşılaşmadığı sorunları çözmede hem geleneksel hem de geleneksel olmayan yöntemleri kullanmak.

iletişim: Duygu ve düşüncelerini açık ve etkili bir şekilde yazı ve söz ile dile getirme sürecidir. Başka bir ifade ile iletişim, gönderici ve alıcı konumundaki iki insan ya da insan grubu arasında gerçekleşen duygu, düşünce, davranış ve bilgi alışverişidir (Milner, 1989). Illetişim becerileri olan eğitim yöneticisi şu davranışları ortaya koymalıdır (Partnership for 21st Century Skills, 2008):a)Çalışanlarını dinler. b)Çalışanlarla iletişim kurarken kullandığı beden dili olumludur. c) Çalışanlarla açık iletişim kurar. d)Düşündüklerini çalışanların anlayacağı şekilde ifade eder. e)Çalışanları anlamak için çaba sarf eder. f)Kullandığı dille çalışanları motive eder. g)Çalışanlarını nasıl ikna edeceğini bilir. h) Çalışanları ile empati kurar. ı)Kurum dışından kişilerle iletişim kurmada zorlanmaz. 
İşbirliği: Işbirliği; kurumdaki çalışanların, birtakım ortak sorunların çözümü için bir araya gelip görüş alışverişinde bulundukları ve var olan sorunları çözmek için birlikte hareket ettikleri bir süreçtir. Bu süreçte taraflar, birbirlerinin ihtiyaçlarını, çıkarlarını ve güçlüklerini anlamaktadırlar ve ortak amacı başarabilmek için taviz verme, esnek davranma, gönüllü olarak çalışma ve sorumluluk alma gibi becerileri gösterme eğilimdedirler (Özgenç, 2012).

İşbirliği içerisinde çalışması gereken eğitim yöneticisi şu becerileri göstermelidir (Partnership for 21st Century Skills, 2008): a)Farklı takımlarla, etkin ve saygı içinde çalışma yeteneğini gösterme, b)Ortak hedefe ulaşmak için gerekli esneklik, isteklilik ve yardımı sağlama, c)Ortak çalışmada çalışanların sorumluluklarını nasıl paylaşacağını ve her bir takım üyesinin ne kadar katkı yapacağını bilme.

\section{Okur-yazarlık Becerileri}

Bilgi okur-yazarlığı: Bilgi okur-yazarlığı problemlerin veya sorunların çözümü için doğru ve yaratıcı bilgiyi kullanarak ve eleştirel ve etkin değerlendirmeler yaparak yeterli ve etkili bilgiye erişebilmek, bilginin kullanımında ve erişiminde yasal/etik çerçeve hakkında derin bir anlayışa sahip olmak (Partnership for 21st Century Skills, 2008). Bir başka tanımla bilgi okuryazarlığı, bir konu veya sorunu ele almak amacıyla bilgiyi belirleme, bulma, değerlendirme, düzenleme ve etkin bir biçimde yaratma, kullanma ve iletme yeteneğidir (Demiralay \& Karadeniz, 2008).

Bilgiye erişim ve bilgiyi değerlendirmede; bilgiye verimli (zaman açısından) ve etkin (kaynaklar açısından) bir şekilde erişme ve bilgiyi eleştirel ve yetkin bir şekilde değerlendirme önemlidir. Bilgi okuryazarlığına sahip bireyde; a)Hangi genişlikte bilgiye intiyaç duyulduğunu bilme, b)ihtiyaç duyduğu bilgiye etkili ve verimli şekilde ulaşma, c)Bilgi ve onun kaynaklarını eleştirel olarak değerlendirme, d)Bir kişinin sahip olduğu bilgi tabanından gerekli bilgiyi seçme ve birleştirme, e)Belirli bir amacı gerçekleştirmek için bilgiyi etkin kullanma, f)Bilgiyi kullanırken çevresindeki ekonomik, yasal ve sosyal olayları anlama ve bu bilgiye etik ve yasal olarak ulaşma becerilerinin bulunması gerekir.

Medya okur-yazarlığı: Medya okur-yazarlığı hangi medya mesajlarının, ne amaçla ve hangi araçları, özellikleri, eğilimleri kullanarak verildiğini anlamak; kişilerin inanç, davranış ve değerlerini nasıl etkilediğini ve farklı mesajların kişisel olarak nasıl yorumlanabileceğini bilmek olarak tanımlanabilir (Partnership for 21st Century Skills, 2008). Medya okur-yazarlığı, medya mesajlarının doğru algılanması, eleştirel bir bakış açısıyla alınabilmesi, gerçeklik-kurgusalık ayrımının yapılabilmesi, medyanın sunduğu dünyanın gerçeğin kendisi olmayabileceğinin anlaşılması, medyanın yönlendirme ve yönetme fonksiyonlarııın olduğunun farkına varılabilmesi, mesajı gönderenlerin kendi düşüncelerini empoze etme gayreti içinde olabileceklerinin değerlendirilmesidir. Yani medya okuryazarlığı, kaynağı her ne olursa olsun, bilgiyi değerlendirip onu yerinde kullanabilen bireyler olmayı, böyle bireyler yetiştirmeyi hedeflemektedir (RTÜK, 2016). 21. yy. medya becerileri kişilerin medya mesajlarına ulaşması, anlaması ve analiz etme becerilerini temel alır. Medyayı analiz etmek için (Partnership for 21st Century Skills, 2008); a)Medya mesajlarının hem nasıl hem de niçin inşa edildiğini anlamak ve medyanın amacının ne olduğunu ortaya çıkarmak, b)inançların ve davranışların medya tarafindan nasıl etkilendiğini ve kabul edilmeyen ve edilen bakış açılarının medya tarafindan nasıl değer yarattğını, ve farklı mesajların kişiler tarafindan nasıl yorumlandığını incelemek, c)Medyanın kullanımı ve erişimini çevreleyen yasal/etik konuların anlaşılabilmesi için temel bir anlayış geliştirmek gerekmektedir.

Teknoloji okur-yazarlığı: Teknoloji okur-yazarlığı bilgi teknolojisinin işlevini yerine getirmek ve uygun iletişim ağları ve/veya araçları kullanarak bilgiyi yaratmak, değerlendirmek, entegre etmek, yönetmek ve erişmek için dijital teknolojileri kullanmak, bilginin kullanımında ve erişiminde yasal/etik çerçeve hakkında derin bir anlayışa sahip olmak ve bilgiyi araştırma, geliştirme ve düzenlemede teknolojiyi araç olarak kullanmak olarak tanımlanabilir (Partnership for 21st Century Skills, 2008). Teknoloji okuryazarlığı bireylerin, teknoloji ile kendileri ve toplum arasındaki ilişkinin anlaşılmasında gerekli olan entelektüel süreç, yeterlilik ve düzenin tümü olarak da tanımlanabilir (Odabaşı, 2016).

Teknoloji okur-yazarlığı becerisine sahip bir bireyde iletişim bilgilerini düzenleme, değerlendirme ve araştırma için teknolojiyi kullanma, bilgi ekonomisinin işlevlerini başarılı bir şekilde yerine getirmek için bilgiyi yaratma, değerlendirme, entegre etme, yönetme ve erişim için en uygun sosyal ağları ve iletişim-ağ araçlarını yani dijital teknolojileri kullanma becerilerinin olması gerekir (Partnership for 21st Century Skills, 2008).

\section{Sosyal ve Mesleki Beceriler}

Esneklik ve Kolay Uyum Sağlama: Kolay uyum sağlayabilme; çeşitli rollere ve sorumluluklara kolay adapte olabilme, değişen öncelikler ve belirsizlikler karşısında etkili çalışabilme (Partnership for 21st Century Skills, 2008) olarak tanımlanırken; örgütsel esneklik, bir örgütün, çalışanlar ve yöneticiler tarafindan, öğrenme yolu ile sürekli geliştirilerek, çevredeki değişimlere doğru zamanda doğru cevap verebilmesi yeteneği olarak tanımlanabilir(Ceylan, 2001). 
İnisiyatif kullanma ve özyönetim: İnisiyatif kavramı çalışanların, kendi oluşturdukları amaçlarla, rol gerekliliklerinden öte sorumluluklar alarak kendi bireysel performanslarını ve örgütlerinin etkililiğini artırmalarına odaklanan bir kavramdır (Akın, 2014). Özyönetim ise, geleneksel iş organizasyonunun aksine, çalışanların işyerinde -müşteri ilişkileri, genel üretim yöntemleri, zamanlama ve işbölümü gibi konuları kapsayan- karar alma sürecini bizzat elinde bulundurmasını ifade eder (Beyerlein, 1994) .

İnisiyatif kullanma ve özyönetim becerisine sahip bir eğitim yöneticisi şu becerileri göstermelidir (Partnership for 21st Century Skills, 2008).a)Kişinin kendi öğrenme intiyacını belirlemesi, b)Profesyonel düzeyden ileri beceri düzeylerine inisiyatif gösterebilmesi, c)Doğrudan gözlem olmaksızın görevlerin tamamlanarak ve önceliklendirilerek tanımlandırılması, d)Zamanı verimli kullanma ve iş yükünü yönetebilme, e)Yaşam boyu bir süreç olarak öğrenmeye bağlılık sergileme.

Sosyal ve kültürler arası beceriler: Sosyal ve kültürler arası beceriler; başkaları ile uygun ve verimli çalışma, uyum sağlamak için grupların kolektif zekâsından faydalanma, işin kalitesi ve inovasyonu artırmak için farklı bakış açılarını kullanarak, kültürel farklılıklar arasında köprü kurmak olarak tanımlanabilir. 21. yy. sosyal ve kültürler arası beceriler, meslektaşları ile iyi çalışmak, profesyonelce kendini sunabilmek, saygı ve farklı kültürleri kucaklama yetenekleri olarak özetlenebilir. Sosyal ve kültürel becerile sahip bir yöneticinin; a)Ne zaman konuşacağını, ne konuşacağını bilmesi, b)Profesyonel bir şekilde tavır sergilemesi ve kendi kendini yönetmesi, c)Sosyal ve kültürel geçmişleri farklı bireylerle uyum içerisinde çalışması, d)Farklı değer ve fikirlere açık olması, e)Sosyal ve kültürel faklılıkların yarattğı yeni fikirleri kullanabilmesi ve bu faklııkları yenilik yapmak için firsat olarak görmesi gerekir (Partnership for 21st Century Skills, 2008).

Üretkenlik ve Hesapverebilirlik: Hesapverebilirlik bir kurumdaki görevlilerin yetki ve sorumluluklarının kullanılmasına ilişkin olarak ilgili kişilere karşı cevap verebilir olma, bununla birlikte eleştiri ve cevapları dikkate alarak bu yönde hareket etme ve bir başarısızlık, yetersizlik ya da hilekarlık durumunda sorumluluğu üzerine alabilme gerekliliğidir (Schater, 2000). İ̧̧ ortamında hedefler doğrultusunda toplantılar yapabilme, zamanı yönetebilme, etik çalışma, çalışma arkadaşları ve paydaşlarla ortak çalışma bu kategoride değerlendirilebilir. Engeller ve rekabet baskısı karşısında bile yılmamak, amaçlanan sonuca ulaşmak için plan yapmak, planı yönetmek ve öncelikleri belirlemek, yetenekleri doğrultusunda yüksek kaliteli ürünler vermek eğitim yöneticilerinin sahip olması gereken en temel niteliklerdir. Bunların dışında yöneticilerin şu davranışları sergilemeleri beklenir (Partnership for 21st Century Skills, 2008): a)Olumlu ve etik çalışma, b)Zaman ve projeleri etkili yönetme, c)Aktif katılım, hem güvenilir, hem dakik olma, d)Takım çalışması yapma ve etkili bir işbirliği yapma, e)Karşılıklı saygı ve takdir edebilme yeteneği, f)Sonuçların sorumluluğunu üstlenebilme.

Liderlik ve Sorumluluk: Liderlik çok kapsamlı bir kavramdır ama burada liderlik denildiğinde yöneticiden beklenen, kurumsal hedefler doğrultusunda kişilerarası ve problem çözme becerilerini kullanarak çalışanları etkilemek ve yönlendirmek şeklindedir. Liderlik ve sorumluluk becerileri; bireylerin toplumun ilgi ve istekleri doğrultusunda çalışmasıdır. Kurumda çalışanların kişisel problemlerini çözmede onlara liderlik etmek, ortak hedeflere ulaşmak için kaldıraç güç olmak, kendi üzerlerine düşen görevi yerine getirmek için elinden geleni yapmalarını sağlamak ve onlara ilham vermek, dürüst ve etik davranarak diğer öğrencilerin bundan etkilenmelerini sağlamaktır (Partnership for 21st Century Skills, 2008).

Görüldüğü gibi 21.yy ortak çalışma grubu tarafindan "21. yy becerileri" ve bu becerilere sahip olan bireylerin göstermesi gereken davranışlar ayrı ayrı tanımlanmıştır. Bu çalışmanın amacı bu tanımlar ve alanyazından yola çıkarak eğitim yöneticilerinin 21. yy. becerilerine ne derece sahip olduklarını ortaya koyacak geçerli ve güvenilir bir ölçme aracı geliştirmektir.

\section{Yöntem}

Bu bölümünde araştırmaya katılanların demografik özellikleri verilecektir. Bunun yanısıra, veri toplama aracının nasıl geliştirildiği ve verilerin nasıl analiz edildiği sunulacaktır.

\section{Katilımcılar}

Bu araştırmada, internet üzerinden on-line ölçek ile Milli Eğitim Bakanlığına bağlı özel ve devlet okullarında çalışan toplam 361 öğretmene ulaşılmıştı. Araştrrmada belli bir hedef evrene genelleme kaygısı olmadığı için örneklem seçilmemiş, Milli Eğitim Bakanlığına bağı özel ve devlet okullarında çalışan gönüllü öğretmenlerden araştırmaya katılmaları istenmiştir. Tablo 1'de kathlımcıların demografik bilgilerine ilişkin özellikler sunulmaktadır. 
Tablo1. Katilımcıların demografik özellikleri

\begin{tabular}{llcc}
\hline Değişkenler & & $\mathrm{f}$ & $\%$ \\
\hline \multirow{2}{*}{ Cinsiyet } & Kadın & 173 & 48 \\
& Erkek & 188 & 52 \\
\hline \multirow{4}{*}{ Yaş } & 21-30 yaş arası & 81 & 22 \\
& 31-40 yaş arası & 155 & 43 \\
& 41-50 yaş arası & 100 & 28 \\
& 51 ve üzeri & 25 & 7 \\
\hline \multirow{4}{*}{ Eğitim durumu } & Ön lisans & 6 & 2 \\
& Lisans & 301 & 83 \\
& Yüksek Lisans & 45 & 12 \\
& Doktora & 9 & 3 \\
\hline \multirow{4}{*}{ Kıdem } & $1-10$ yıl & 131 & 37 \\
& $11-20$ yıl & 155 & 43 \\
& $21-30$ yıl & 62 & 17 \\
& 31 yıl ve üzeri & 13 & 3 \\
\hline
\end{tabular}

Eğitim Yöneticisi 21. yy. Becerileri Ölçeği geliştirmeye odaklanan bu çalışmada örneklemin, faktör analizi için uygun olup olmadığına Kaiser-Meyer-Olkin (KMO) ve Barlett Sphericity testi kullanılarak bakılmıştr. Çalışmada KMO değeri .986 ve Barlett değeri ise $43626,274(p=.000)$ olarak bulunmuştur. Örneklemden elde edilen verinin faktör analizine uygun olması için KMO değerinin .60'tan yüksek ve Barlett değerinin de anlamlı olması gerekmektedir (Büyüköztürk, 2004). Ayrıca örneklemden elde edilen verilerin normal dağıııp dağılmadığı, saçılım diyagramları ve betimsel istatistikler ile incelenmiştir. Örneklemden elde edilen verilerin ortalaması 3.46 , ortancası 3.51 , çarpıklık katsayısı 0.400 ve basıklık katsayısı 0.293 olarak bulunmuştur. Basıklık ve çarpıklık katsayısının 1'den küçük olması ve ortalama ve ortancanın birbirine yakın olması verilerin normal dağılıma yakın olduğunu göstermektedir. Dolayısıyla araştırmadaki örneklem büyüklüğünün, geçerlik ve güvenirlik çalışması yapabilmek için kabul edilebilir düzeyde olduğu söylenebilir.

\section{Veri Toplama Aracı}

Eğitim Yöneticisi 21.yy Becerileri Ölçeği (21.yy. EYBÖ) taslağı iki bölümden oluşmaktadır. Birinci bölümde katlımcıların demografik bilgileri yer almaktadır. İkinci bölümde ise, Eğitim Yönetici 21. yy. EYBÖ bulunmaktadır. Bu ölçek, üç temel beceri altında toplanabilen 12 alt boyuta ilişkin toplam 110 maddeden oluşmuştur. "Öğrenme ve Yenilik Becerileri" boyutunun altında "yaratıclık ve yenileşme", "eleştirel düşünme ve problem çözme", "iletişim" ve "işbirliği" olmak üzere dört alt boyut; "Okur-Yazarlık Becerileri” boyutunun altında "bilgi okur-yazarlığı", "medya okur-yazarlığı" ve "teknoloji okuryazarlığı" olmak üzere üç alt boyut ve "Yaşam ve Mesleki Beceriler" boyutunun altında "özyönetim ve inisiyatif", "üretkenlik ve hesapverebilirlik", "liderlik ve sorumluluk" "esneklik ve kolay uyum sağlama" ve "sosyal ve kültürlerarası beceriler" olmak üzere beş alt boyut bulunmaktadır. Ölçekte yaratıcılık ve yenileşme alt boyutunda 9, eleştirel düşünme ve problem çözme alt boyutunda 11 , iletişim alt boyutunda 12, işbirliği alt boyutunda 9, bilgi okur-yazarlığı alt boyutunda 7, medya okuryazarlığı alt boyutunda 7, teknoloji okur-yazarlığı alt boyutu altında 7, öz yönetim ve inisiyatif alt boyutunda 11, üretkenlik ve hesapverebilirlik alt boyutunda 11, liderlik ve sorumluluk alt boyutunda 11 , esneklik ve kolay uyum sağlama alt boyutunda 9 ve sosyal ve kültürlerarası beceriler alt boyutunda 6 madde bulunmaktadır. Belirlenen maddelerin ölçülmek istenen özelliği ölçmede nitelik ve nicelik açısından yeterli olup olmadığını belirlemek başka bir ifade ile kapsam geçerliliğini sağlamak için yöneticilik becerileri üzerine çalışan 6 alan uzmanından geri bildirimler alınmıştır. Eğitim yöneticilerinin 21. yy. becerilerine ne derece sahip oldukları konusunda öğretmen görüşüne dayalı olan bu ölçek, 5'li derecelendirme (1= Hiç, 5= Tamamen) kullanılarak hazırlanmıştır.

\section{Veri Analizi}

Ölçeğin katılımcılardan elde edilen puanların oluşturduğu faktör yapısının, alan yazına dayalı olarak belirlenen faktör yapısını doğrulayıp doğrulamadığı incelemek amacıyla Doğrulayıcı Faktör Analizi (DFA-Confirmatory Factor Analysis), Lisrel 8.8 programı kullanılarak incelenmiştir. Hata payı .05 olarak belirlenmiştir. Doğrulayıcı Faktör Analizi, ölçek geliştirme sürecinin ilk aşamalarında son derece etkilidir (Şimşek, 2007). Doğrulayıcı Faktör Analizi araştırmacı tarafindan belirlenen modelin test edilmesini amaçlar (Child, 1975; Hoyle, 1995). 21.yy Eğitim Yöneticisi Becerilerine yönelik olarak geliştirilen ölçme aracında araştırmacılar tarafindan ikinci düzey (second order) doğrulayıcı faktör analizi kullanılmıştır. İkinci düzey doğrulayıcı faktör analizinde, gözlenen değişkenlerden örtük değişkenlere doğru tek yönlü doğrusal ilişkilerin tanımlanmasının yanı sıra gözlenen değişkenlerden yine gözlenen değişkenlere tek yönlü doğrusal ilişkiler de 
tanımlanır (Şimşek, 2007). Söz konusu çalışmada "yaratıcılık ve yenileşme", "eleştirel düşünme ve problem çözme" ,"iletişim" , "işbirliği", "bilgi okur-yazarlığı", "medya okur-yazarlığı", "teknoloji okuryazarlığı" "özyönetim ve inisiyatif", "üretkenlik ve hesapverebilirlik", "liderlik ve sorumluluk", "esneklik ve kolay uyum sağlama" ve "sosyal ve kültürlerarası beceriler" birinci düzey örtük değişkenler olarak tanımlanırken; “Öğrenme ve Yenilik Becerileri”, "Okur-Yazarlık Becerileri" ve "Yaşam ve Mesleki Beceriler" ikinci düzey örtük değişkenler olarak tanımlanmıştır.

DFA ile elde edilen modelin yeterliliğinin, birçok uyum indeksi ile birlikte ele alınarak değerlendirilmesi önerilmektedir. Bu çalışmada alan yazın taraması sonucu ortaya konulan üç ana föktör altında belirlenen toplanan 12 yapının doğrulanmasında şu uyum indeksleri kullanılmıştr. Ki-Kare İyilik Uyumu (Chi-Square Goodness of Fit X2), Karşılaştırmalı Uyum İndeksi (Comperative Fit Index), Normlaştrıımış Uyum İndeksi (Normed Fit Index, NFI), Normlaştıılmamış Uyum Indeksi (Not Normed Fit Index, NNFI), Standardize edilmiş Arttk Ortalamaların Karekökü (Standardized Root Mean Square Residuals, SRMR) ve Yaklaşık Hataların Ortalama Karekökü (Root Mean Square Error of Approximation, RMSEA).

21.yy. EYBÖ ölçeğinin ölçtükleri özellik açısından kişileri ayırt etmede ne kadar yeterli olduklarının belirlenmesi amacıyla şu analizler yapılmıştır: a) ölçeğin geçerlik çalışması için DFA yapılmıştır ve uyum istatistikleri verilmiştir. b) Modeldeki maddelerin standartlaştrılmış faktör yükleri, hata varyansları, $\mathrm{t}$ değerleri ve açıklanan toplam varyansları hesaplanmış ve model çizilmiştir. c) Cronbach Alpha, Spearman Brown ve Guttman iç tutarlıık katsayısı kullanılarak ölçeğin genelinin ve alt faktörlerin güvenirliği hesaplanmış d) ölçeğin faktör puanlarının ortalama ve standart sapma değerleri ile faktörler arası korelasyonlar için Pearson Momentler Çarpımı hesaplaması yapılmıştır.

\section{Bulgular ve Yorumlar}

\section{1.yy. EYBÖ Geçerlilik Çalışması}

21.yy EYBÖ’nün faktör yapısını araştırmak amacıyla yapılan DFA sonucunda standartlaştrıılmış faktör yükleri 1.00'ın üzerinde olan 14 madde (S8, S14, S15, S40, S44, S47, S50, S54, S63, S69, S84, S86, S94, S101) atılmış ve sonrasında yeni model oluşturulmuştur. Yeni modelde yaratıcılık ve yenileşme alt boyutunda 8 , eleştirel düşünme ve problem çözme alt boyutunda 11, iletişim alt boyutunda 11, işbirliği alt boyutunda 9, bilgi okur-yazarlığı alt boyutunda 7, medya okuryazarlığı alt boyutunda 5, teknoloji okur-yazarlığı alt boyutu altında 5, öz yönetim ve inisiyatif alt boyutunda 9 , üretkenlik ve hesapverebilirlik alt boyutunda 9 , liderlik ve sorumluluk alt boyutunda 9 , esneklik ve kolay uyum sağlama alt boyutunda 8 ve sosyal ve kültürlerarası beceriler alt boyutunda 5 madde olmak üzere toplam 96 madde kalmıştr. Bu modelin sonucunda ortaya çıkan uyum indeksi değerleri ve bu değerler için kabul kesme noktaları dikkate alınarak yapılan değerlendirme sonuçları Tablo. 2'de sunulmuştur.

\section{Tablo 2. Modele ilişkin uyum indeksleri}

\begin{tabular}{lcc}
\hline Uyum İndeksleri & Değerler & Durum \\
\hline Ki kare X2/sd & $9903.26 / 4449=2.22$ & Mükemmel Uyum \\
Karşılaştırmalı Uyum İndeksi CFI & 0.99 & Mükemmel uyum \\
Normlaştrılmış Uyum İndeksiNFI & 0.99 & Mükemmel uyum \\
Normlaştrılmamış Uyum İndeksi NNFI & 0.99 & Mükemmel uyum \\
Standardize edilmiş Arttk Ortalamaların Karekökü SRMR & 0.032 & Mükemmel uyum \\
Yaklaşık Hataların Ortalama Karekökü RMSEA & 0.070 & İyi uyum \\
\hline
\end{tabular}

Tablo 2'de görüldüğü gibi $\chi 2=9903.26$ (sd=4449, $p>$.05) ve $\chi 2 / s d$ değeri 2.22 'dir. Küçük örneklemlerde $\chi 2 / s d$ oranının 2.5ve altında olması mükemmel uyuma, 5 ve altında olması iyi uyuma karşılık gelmektedir (Kline, 2005; Tabachnick, 2001). Bu çalışmada elde edilen 2.22 değeri, alan yazın taramasına dayalı olarak belirlenen faktör yapısının kabul edilebilir bir uyum sergilediğini göstermektedir. Analizde diğer uyum indeksleri incelendiğinde RMSEA'nın 07 ve SRMR'nin de .032 olduğu belirlenmiştir. Jöroskogve Sörbom (1993)'a göre RMSEA değerinin .05'ten küçük olması mükemmel uyuma, 0.8'den küçük olması iyi uyuma işaret eder (Jöreskog, 1993). Standardize edilmiş RMR değerinin 0.032 olduğu görülmektedir. Standardize edilmiş RMR değerinin .05'in altında olması mükemmel uyuma (Brown, 2006) ve .10'un altında olması ise zayıf uyuma karşılık gelmektedir (Çokluk, Şekercioğlu, \& Büyüköztürk, 2010). Bu çerçevede, SRMR değerinin mükemmel uyuma sahip olduğu ifade edilebilir. Son olarak NFI, NNFI ve CFI değerlerinin .95'in üzerinde olması mükemmel uyuma, .90'ın üzerinde olması iyi uyuma karşılık gelmektedir (Sümer, 2000). Çalışmada elde edilen değerlerin, yukarıda belirtilen kesme noktalarına eşit ve yakın olmasının modelin yapısı ve veriler arası iyi bir uyumu işaret ettiği söylenebilir. Şekil 2'de 21.yy. EYBÖ’nün üç ana faktör altnnda toplanan 12 alt boyut ile, faktörler ile maddeler arasındaki ilişkileri gösteren yol şeması verilmiştir. Faktörden (gizil değişken) maddeye (gözlenen değişken) doğru çizilen tek yönlü doğruların üzerindeki değerler, faktörlerin madde üzerindeki nedensel etki büyüklüklerini diğer

| Kastamonu Eğitim Dergisi, 27(3), 2019| 
bir deyişle faktör yüklerini; maddelere sol taraftan dışarıdan gelen oklar üzerindeki değerler hata varyanslarını göstermektedir. Faktörler arası çift yönlü oklar üzerinde yer alan değerler ise faktörler arası korelasyon katsayılarını yani ortak değişkenlik değerlerini göstermektedir.

Standartlaştırılmış faktör yükleri ( $\lambda=$ Lambda), gizli değişkendeki bir birim değiş̧ikliğin, gözlenen değişkende ne kadar değişkenliğe yol açacağı başka bir deyişle gözlenen değişkenle, ilgili gizil değişken arasındaki ilişki konusunda fikir vermektedir. Bu değerlerin yüksek olması gizil ve gözlenen değişken arasında güçlü bir ilişki olduğunu göstermektedir (Çokluk, Şekercioğlu, \& Büyüköztürk, 2010). Tablo 3 incelendiğinde, faktör yük değerlerinin 0.72 ile 0.99 arasında değiştiği görülmektedir. Her bir faktöre ilişkin yük değerleri incelendiğinde, maddelerin ilgili faktör ile iyi düzeyde ilişki içerisinde olduğu söylenebilir. Tabloda verilen gizil değişkenlerin, gözlenen değişkenleri açıklama durumuna ilişkin $\mathrm{t}$ değerlerinin 11.06 ile 13.11 arasında değiştiği görülmektedir. Tüm $t$ değerleri .01 düzeyinde anlamlıdır. R2 değerleri ise gözlenen değişkendeki açıklanan varyansın ne kadarının gizil değişkenden kaynaklandığını göstermektedir (Çokluk, Şekercioğlu, \& Büyüköztürk, 2010). Tablodaki R2 değerlerinin 0.42 ile 0.79 arasında ve kabul edilebilir düzeyde oldukları görülmektedir. Sonuç olarak; Şekil 2'deki ölçek yol şeması, Tablo 2'deki bulgular ışığında, ölçeğin kabul edilebilir düzeyde geçerliğe sahip olduğu söylenebilir.

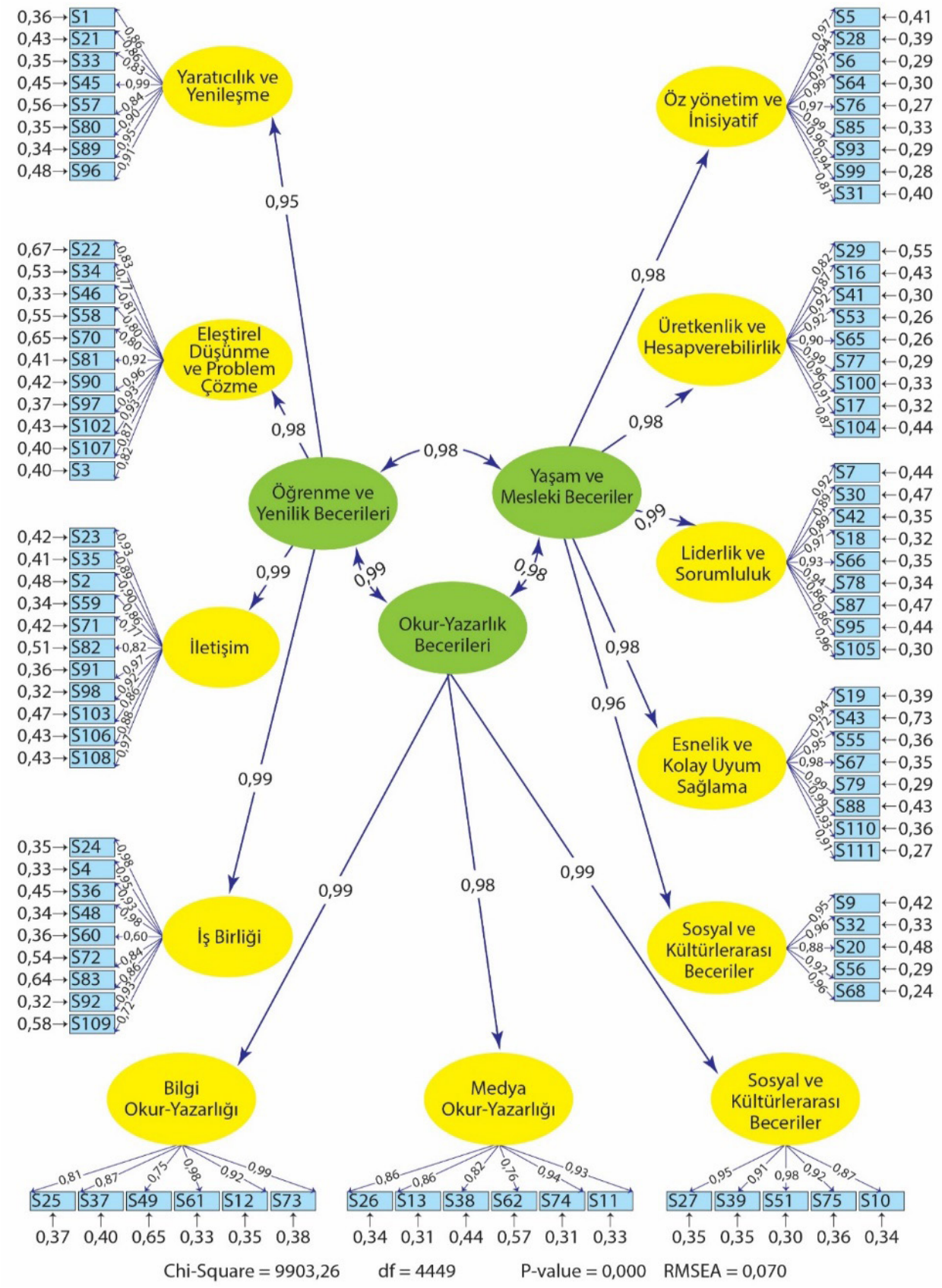

Şekil 2. Eğitim yöneticisi 21. yy. becerileri ölçeği doğrulayıcı faktör analizi sonuçları 
21.yy. ЕYBÖ’nün yol şemasına göre belirlenen faktör yükleri, faktörlerin gözlenen değişkenleri açıklama oranları ve manidarlık düzeylerine ilişkin t değerleri Tablo 3'te sunulmaktadır.

Tablo 3. Ölçek maddelerinin standartlaştırılmış faktör yükleri, hata varyansları, $t$ - değerleri ve açıklanan toplam varyans değerleri

\begin{tabular}{|c|c|c|c|c|c|c|c|c|c|}
\hline $\begin{array}{l}\text { Madde } \\
\text { No }\end{array}$ & $\begin{array}{l}\text { Standartlaştrinlmıs } \\
\text { Faktör Yakkleri } \lambda\end{array}$ & $\begin{array}{l}\text { Hata } \\
\text { varyansi }\end{array}$ & de & $\mathbf{R}^{2}$ & $\begin{array}{l}\text { Madde } \\
\text { No }\end{array}$ & $\begin{array}{l}\text { Standartlaşturilmis } \\
\text { Faktör Yukleri } \lambda\end{array}$ & $\begin{array}{l}\text { Hata } \\
\text { varyansı }\end{array}$ & $\begin{array}{l}\mathrm{t}- \\
\text { değeri }\end{array}$ & $\mathbf{R}^{2}$ \\
\hline S1 & 0.86 & 0.35 & 12.19 & 0.68 & S62 & 0.76 & $\mathbf{0 . 5 7}$ & 12.94 & 0.51 \\
\hline S21 & 0.87 & 0.42 & 12.36 & 0.64 & S74 & 0.94 & 0.32 & 12.03 & 0.74 \\
\hline $\mathbf{S 3 3}$ & 0.84 & 0.35 & 12.26 & 0.67 & S11 & 0.94 & 0.33 & 12.09 & 0.73 \\
\hline S45 & 0.89 & 0.45 & 12.38 & 0.64 & S27 & 0.95 & 0.35 & 12.23 & 0.72 \\
\hline S57 & 0.83 & 0.56 & 12.70 & 0.55 & S39 & 0.91 & 0.35 & 12.31 & $\begin{array}{l}0.71 \\
\end{array}$ \\
\hline $\mathbf{S 8 0}$ & 0.89 & 0.37 & 12.15 & 0.68 & S51 & 0.98 & 0.30 & 11.90 & 0.76 \\
\hline S89 & 0.94 & 0.34 & 11.90 & 0.72 & S75 & 0.92 & 0.36 & 12.36 & 0.70 \\
\hline $\mathbf{S 2 2}$ & 0.83 & 0.67 & 13.00 & 0.51 & S5 & 0.96 & 0.42 & 12.68 & 0.69 \\
\hline S34 & 0.78 & 0.52 & 12.95 & 0.54 & S28 & 0.94 & 0.40 & 12.69 & 0.69 \\
\hline S46 & 0.82 & 0.33 & 12.59 & 0.67 & S6 & 0.96 & 0.29 & 12.35 & 0.76 \\
\hline S58 & 0.81 & 0.54 & 12.94 & 0.54 & S64 & 0.99 & 0.29 & 12.29 & 0.77 \\
\hline S70 & 0.80 & 0.65 & 13.02 & 0.50 & S76 & 0.97 & 0.27 & 12.23 & 0.78 \\
\hline S81 & 0.92 & 0.41 & 12.59 & 0.67 & S85 & 0.99 & 0.34 & 12.45 & $\begin{array}{l}0.74 \\
\end{array}$ \\
\hline S90 & 0.96 & 0.42 & 12.53 & 0.69 & $\mathbf{S 9 3}$ & 0.97 & 0.29 & 12.33 & 0.76 \\
\hline S97 & 0.92 & 0.37 & 12.49 & 0.70 & S99 & 0.95 & 0.26 & 12.25 & 0.78 \\
\hline S102 & 0.92 & 0.43 & 12.62 & 0.66 & S31 & 0.82 & 0.38 & 12.83 & 0.64 \\
\hline S107 & 0.87 & 0.40 & 12.64 & 0.66 & 529 & 0.83 & 0.53 & 12.98 & 0.57 \\
\hline $\mathbf{S 3}$ & 0.82 & 0.40 & 12.74 & 0.63 & S16 & 0.87 & 0.43 & 12.83 & 0.64 \\
\hline $\mathbf{5 2 3}$ & 0.93 & 0.42 & 12.87 & 0.68 & S41 & 0.93 & 0.28 & 12.38 & 0.75 \\
\hline S35 & 0.89 & 0.41 & 12.91 & 0.66 & $\mathbf{S 5 3}$ & 0.93 & 0.24 & 12.18 & 0.78 \\
\hline S2 & 0.90 & 0.49 & 12.99 & 0.62 & S65 & 0.91 & 0.24 & 12.27 & 0.77 \\
\hline S59 & 0.86 & 0.33 & 12.83 & 0.69 & S77 & 0.99 & 0.29 & 12.27 & 0.77 \\
\hline S71 & $\begin{array}{l}0.78 \\
\end{array}$ & 0.41 & 13.04 & 0.59 & $\mathbf{S 1 0 0}$ & 0.95 & 0.35 & 12.53 & 0.72 \\
\hline $\mathbf{S 8 2}$ & 0.83 & 0.51 & 13.07 & 0.58 & S17 & 0.91 & 0.33 & 12.56 & 0.72 \\
\hline S91 & 0.96 & 0.37 & 12.75 & 0.72 & S104 & 0.87 & 0.44 & 12.84 & 0.63 \\
\hline S98 & 0.91 & 0.32 & 12.72 & 0.72 & S7 & 0.93 & 0.42 & 12.78 & 0.67 \\
\hline S103 & 0.86 & 0.47 & 13.01 & 0.61 & S30 & 0.89 & 0.46 & 12.89 & 0.63 \\
\hline S106 & 0.88 & 0.43 & 12.94 & 0.65 & $\mathbf{S 4 2}$ & 0.89 & 0.35 & 12.72 & 0.69 \\
\hline S108 & 0.97 & 0.43 & 12.83 & 0.69 & S18 & 0.96 & 0.33 & 12.53 & 0.74 \\
\hline $\mathbf{S 2 4}$ & 0.98 & 0.35 & 12.45 & 0.73 & S66 & 0.93 & 0.35 & 12.64 & 0.71 \\
\hline S4 & 0.95 & \begin{tabular}{|l|l|}
0.33 \\
\end{tabular} & 12.42 & 0.73 & $\begin{array}{l}\text { S78 } \\
\end{array}$ & 0.94 & 0.34 & 12.61 & 0.72 \\
\hline S36 & 0.93 & 0.45 & 12.74 & 0.66 & S87 & 0.86 & 0.46 & 12.92 & 0.61 \\
\hline S48 & 0.98 & 0.34 & 12.41 & 0.74 & S95 & $\begin{array}{l}0.87 \\
\end{array}$ & 0.43 & 12.87 & 0.64 \\
\hline S60 & 0.87 & 0.36 & 12.66 & 0.68 & S105 & 0.95 & 0.30 & 12.46 & 0.75 \\
\hline S72 & 0.84 & 0.53 & 12.95 & 0.57 & S19 & 0.94 & 0.40 & 12.64 & 0.69 \\
\hline $\mathbf{S 8 3}$ & 0.86 & 0.64 & 13.01 & 0.54 & $\mathbf{S 4 3}$ & 0.73 & 0.72 & 13.16 & 0.42 \\
\hline $\mathbf{5 9 2}$ & 0.93 & 0.32 & 12.45 & 0.73 & S55 & 0.95 & 0.36 & 12.54 & 0.71 \\
\hline S109 & 0.72 & $\begin{array}{l}0.58 \\
\end{array}$ & 13.11 & 0.47 & S67 & 0.99 & 0.34 & 12.39 & 0.74 \\
\hline S25 & 0.82 & 0.35 & 12.60 & 0.65 & S79 & 0.99 & 0.29 & 12.21 & 0.77 \\
\hline S37 & 0.88 & 0.39 & 12.57 & 0.66 & S88 & 0.99 & 0.43 & 12.63 & 0.69 \\
\hline S49 & 0.76 & 0.64 & 13.05 & 0.47 & S110 & 0.93 & 0.36 & 12.58 & 0.70 \\
\hline S61 & 0.98 & 0.33 & 12.10 & 0.74 & S111 & 0.91 & 0.27 & 12.33 & 0.75 \\
\hline $\mathbf{S 1 2}$ & 0.92 & $\begin{array}{l}0.36 \\
\end{array}$ & 12.38 & 0.70 & S9 & 0.94 & 0.42 & 12.20 & 0.68 \\
\hline $\mathbf{S 7 3}$ & 0.98 & 0.40 & 12.35 & 0.71 & $\mathbf{S 3 2}$ & 0.96 & 0.33 & 11.79 & 0.74 \\
\hline S26 & 0.86 & 0.34 & 12.35 & 0.69 & $\mathbf{S 2 0}$ & 0.89 & 0.47 & 12.46 & 0.63 \\
\hline $\mathbf{S 1 3}$ & 0.86 & 0.31 & 12.23 & 0.71 & S56 & 0.93 & 0.28 & 11.62 & 0.75 \\
\hline
\end{tabular}

\section{Eğitim Yöneticisi 21.yy. Becerileri Ölçeği Güvenirlik ve İç Tutarııık Çalışması}

Eğitim Yöneticisi 21.yy. Becerileri ölçeğinin güvenirliğini hem genel olarak hem de alt faktörler bazında incelemek için Cronbach Alpha, Spearman Brown ve Guttman iç tutarlıık katsayısı hesaplanmıştır. Bu analiz hesaplamalarına ait sonuçlar Tablo 4'te yer almaktadır. 
Tablo 4. Ölçeğin ve faktörlerinin Cronbach Alpha, Spearman Brown ve Guttman test sonuçları

\begin{tabular}{|c|c|c|c|}
\hline Faktör & $\begin{array}{c}\text { Cronbach } \\
\text { Alpha }\end{array}$ & $\begin{array}{l}\text { Spearman } \\
\text { Brown }\end{array}$ & Guttman \\
\hline \multicolumn{4}{|l|}{ Öğrenme ve Yenilik Becerileri } \\
\hline Yaratıcllk ve Yenileșme & .95 & .94 & .94 \\
\hline Eleștirel Düşünme ve Problem Çözme & .96 & .95 & .94 \\
\hline hetişim & .95 & .95 & .94 \\
\hline Işbirliği & .95 & .94 & .93 \\
\hline \multicolumn{4}{|l|}{ Okur-Yazarlik Becerileri } \\
\hline Bilgi Okur-yazalı̆̆ı & .93 & .93 & .93 \\
\hline Medya Okur-yazarlı̆̆ & .90 & .89 & .89 \\
\hline Teknoloji Okur-yazarlı̆̆ı & .90 & .90 & .87 \\
\hline \multicolumn{4}{|l|}{ Yaşam ve Mesleki Beceriler } \\
\hline Inisiyatif Kullanma ve Özyönetim & .93 & .92 & .90 \\
\hline Üretkenlik ve Hesapverebilirlik & .94 & .94 & .93 \\
\hline Liderlik ve Sorumluluk & .94 & .93 & .92 \\
\hline Esneklik ve Kolay Uyum Sağlama & .94 & .93 & .93 \\
\hline Sosyal ve Kültürlerarası Beceriler & .90 & .90 & .86 \\
\hline Genel Toplam & .99 & .98 & .98 \\
\hline
\end{tabular}

$\mathrm{p}=.01$

Tablo 4 incelendiğinde, Eğitim Yöneticisi 21. yy Becerileri ölçeğinin Cronbach Alpha katsayısının .99, Spearman Brown katsayısının .98 ve Guttman katsayısının .98 olduğu görülmektedir. Ölçeğin faktörlerinin Cronbach Alpha katsayıları .90 ile .96 arasında, Spearman Brown katsayısı .89 ile .95 arasında ve Guttman katsayısı ise .86 ile .94 arasında değişmektedir.

Eğitim Yöneticisi 21.yy. becerileri ölçeğinin iç tutarlığını incelemek amacıyla, faktörlerin toplam puanlarının hem kendi aralarındaki hem de genel ölçek toplam puanı ile olan ilişkilerini gösteren korelasyon değerleri matris tablo olarak ortalama ve standart sapma değerleri ile birlikte Tablo 5'te sunulmuştur.

Tablo 5. Ölçeğin ve faktörlerinin ortalama, standart sapma ve korelasyon değerleri

\begin{tabular}{|c|c|c|c|c|c|c|c|c|c|c|c|c|c|}
\hline \multirow[b]{2}{*}{ Faktor } & \multirow[b]{2}{*}{$\boldsymbol{X}$} & \multirow[b]{2}{*}{$\mathbf{s}$} & \multicolumn{11}{|c|}{ Faktörler Arası Korelasyonlar } \\
\hline & & & 瓷 & 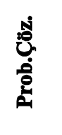 & $\begin{array}{l}\text { 悬 } \\
\text { 曾 }\end{array}$ & 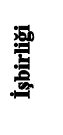 & 兽 & 营 & 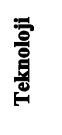 & 害 & 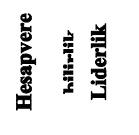 & 煎 & 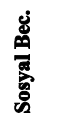 \\
\hline Yarathelluk & 3.40 & .97 & 1 & & & & & & & & & & \\
\hline Prob.Çozz. & 3.35 & .94 & $.94^{*}$ & 1 & & & & & & & & & \\
\hline İetişim & 3.48 & .95 & $.92^{*}$ & $.94^{*}$ & 1 & & & & & & & & \\
\hline Işhirliği & 3.45 & .97 & .93 & $.95^{\circ}$ & $.95^{\circ}$ & 1 & & & & & & & \\
\hline Bilgi & 3.48 & .90 & $.93^{*}$ & $.93^{\circ}$ & $.92^{*}$ & $.93^{\circ}$ & 1 & & & & & & \\
\hline Medya & 3.52 & .87 & $.88^{*}$ & $.85^{\circ}$ & $.84^{*}$ & $.85^{\circ}$ & $.91^{*}$ & 1 & & & & & \\
\hline Teknoloji & 3.58 & .95 & $.83^{*}$ & $.78^{\circ}$ & $.77^{*}$ & $.79^{*}$ & $.84^{*}$ & $.87^{\circ}$ & 1 & & & & \\
\hline Inisiyatif & 3.47 & .89 & $.92^{*}$ & $.93^{\circ}$ & $.93^{*}$ & $.93^{\circ}$ & $.93^{*}$ & $.86^{\circ}$ & $.81^{\circ}$ & 1 & & & \\
\hline Hesap. & 3.49 & .92 & $.94^{*}$ & $.93^{\circ}$ & $.93^{\circ}$ & $.94^{\circ}$ & $.93^{\circ}$ & $.88^{\circ}$ & $.81^{\circ}$ & $.94^{*}$ & 1 & & \\
\hline Liderlik & 3.50 & .92 & $.94^{*}$ & .94 & $.94^{*}$ & $.95^{\circ}$ & $.93^{\circ}$ & $.86^{\circ}$ & $.82^{\prime \prime}$ & $.94^{*}$ & $.95^{\circ}$ & & \\
\hline Esneklik & 3.46 & .92 & $.93^{\circ}$ & $.94^{\circ}$ & $.91^{*}$ & $.93^{\circ}$ & $.93^{*}$ & $.87^{*}$ & $.80^{\circ}$ & $.92^{*}$ & .94 & 1 & \\
\hline Sosyal Bec. & 3.43 & .94 & $.92^{*}$ & $.92^{\circ}$ & $.92^{\circ}$ & $.92^{\circ}$ & $.91^{\circ}$ & $.85^{\circ}$ & $.79^{\circ}$ & $.92^{*}$ & $.93^{\circ}$ & $.90^{\circ}$ & 1 \\
\hline $\begin{array}{l}\text { Genel } \\
\text { Ortalama }\end{array}$ & 3.46 & .89 & $.96^{*}$ & $.97^{*}$ & $.96^{*}$ & $.97^{*}$ & $.96^{\circ}$ & $.91^{*}$ & $.85^{*}$ & $.96^{*}$ & $.97^{*}$ & $.96^{*}$ & $.95^{*}$ \\
\hline
\end{tabular}

Tablo 5’te görüldüğü gibi her bir faktör, hem diğer alt faktörler ile hem de ölçeğin geneli ile anlamlı ilişki içerisindedir. Tüm faktörler arası korelasyon değerlerinin hepsi, pozitif ve yüksek düzeydedir. Ölçekteki faktörlerin genel ölçek puanı ile olan korelasyon değerleri de pozitif ve yüksek düzeydedir. Bu bulgularla, faktörlerin ölçek geneliyle yüksek düzeyde bir ilişki gösterdiği ve ölçme aracının iç tutarlığının yüksek olduğu söylenebilir. 


\section{Tartışma}

Bu araştırmada, öğretmen görüşlerine göre eğitim yöneticilerinin 21.yy. becerilerine ne derece sahip olduklarını ölçmek için geliştirilen ölçeğin geçerlik ve güvenirlik çalışması yapılmıştır. Eğitim Yöneticisi 21. yy. Becerileri ölçeğinin hem genel hem de faktörler bazında Cronbach Alpha güvenirliklerinin yüksek düzeyde olduğu belirlenmiştir. Her bir faktörün hem birbiri ile hem de genel ölçek toplam puanıyla anlamlı ve yüksek düzeyde bir ilişki içinde olduğu saptanmıştr. Bu sonuçlar, ölçeğin güvenirliğinin yüksek olduğuna dair kanıtlar olarak değerlendirilebilir.

21.yу ЕYBÖ ölçeğinin yapı geçerliğinin test edilmesinde doğrulayıcı faktör analizi kullanılmıştır. Modelin standartlaştırılmış faktör yüklerinin yüksek düzeyde olduğu ve t değerlerinin anlamlı olduğu belirlenmiştir. Model değerlendirilmesinde ele alınan uyum indeksleri, veriler ile model yapısı arasında iyi uyuma işaret etmektedir. Modeldeki faktörler arasında belirlenen bazı korelasyon değerleri yüksek düzeyde çıkmıştır. Bunun nedeni, modelin kuramsal yapısından kaynaklı olabilir. Bu ölçek, Türkiye'de görev yapan okul yöneticilerinin 21.yy becerilerini ne derece kullandıklarını belirlemede kullanılabilir. Bu çalışmalarda ayrıca bire bir görüşmeler ve odak grup görüşmeleri ile de yürütülerek okul yöneticilerinin 21.yy becerileri konusunda desteğe ve yardıma intiyaç duydukları alanlar farklı boyutlardan ve detaylı bir biçimde ele alınabilir. Böylece kabul edilebilir uyum gösterdiği saptanan yapının, Türkiye'de nasıl uygulanabileceğine ilişkin zenginleştirilmiş sonuçlar üretilebilir. 21.yy EYBÖ ölçeğinin, okul yöneticilerinin 21. yy becerilerine ne derece sahip olduklarını belirleyerek intiyaç duydukları hizmet-içi eğitimlerin planlanmasında da yararlı olacağı düşünülmektedir.

\section{Kaynakça}

Ağaoğlu, E., Altınkurt, Y., Yılmaz, K., \& Karaköse, T. (2012). Okul Yöneticilerinin Yeterliklerine Illişkin Okul Yöneticilerinin ve Öğretmenlerin Görüşleri (Kütahya Ili). Eğitim ve Bilim, 160-175.

Akın, U. (2014). Okul Müdürlerinin İnisiyatif Alma Düzeyleri ile Öz-Yeterlikleri Arasındaki Ilişki. Educational Administration: Theory and Practice, Kuram ve Uygulamada Eğitim Yönetimi, 20(2), s. 125-149.

Beyerlein, M. a. (1994). Theories of self-managing work teams. Greenwich: JAI Press.

Bozkurt, S., \& Aslanargun, E. (Ağustos 2015). Okul Müdürlerinin Öğretim Programlarının Uygulanmasına Ilişkin Görüşleri. Mersin Üniversitesi Eğitim Fakültesi Dergisi, 11(2).

Bringham, A. (1998). Çocuklarda problem çözme yeteneklerinin geliştirilmesi (2. b.). (A. F. Oğuzkan, Çev.) Ankara: MEB.

Brown, T. (2006). Confirmatory factor analysis for applied research. New York: Guilford Publications.

Büyüköztürk, Ş. (2004). Sosyal bilimler için veri analizi el kitabı. Ankara: PegemA.

Ceylan, C. (2001). Örgütler için esneklik performans modeli oluşturulması ve örgütlerin esneklik analizi. Yayınlanmamış Doktora Tezi. İstanbul: İstanbul Teknik Üniversitesi, Fen Bilimleri Enstitüsü .

Child, D. (1975). The essentials of factor analysis. London: Rinehart \& Winston.

Cottrell, S. (2005). Critical thinking skills: developing effective anaysis and argument. New York: Palgrave McMillan.

Çokluk, Ö., Şekercioğlu, G., \& Büyüköztürk, Ş. (2010). Sosyal bilimler için çok değişkenli istatistik: SPSS ve LISREL uygulamaları. Ankara: Pegem A.

Demiralay, R., \& Karadeniz, Ş. (2008). illköğretimde yaşam boyu öğrenme için bilgi okuryazarlı̆̆ı becerilerinin geliştirilmesi: B6 modeli. ikinci Ulus/ararası Gelecek için Öğrenme Alanında Yenilik Konferansı: e-ögrenme (s. 89-117.). İstanbul: İstanbul Üniversitesi.

Demirel, Ö. (1999). Kuramdan uygulamaya eğitimde program geliştirme. Ankara: Pegem A.

Department of Defense Education Activity-DODEA-. (2014). The 21st Century Principal.

EBA. (2016). img.eba.gov.tr. adresinden alınmıştır

Hoyle, R. H. (1995). Formulating clinical research hypotheses as structrucal equation models: A conceptual overview. Journal of Counsulting and Clinical Psychology, 62( 3), 429-440.

Jöreskog, K. G. (1993). Lisrel 8: Scructural equation modeling with simplis command language. Lincolnwood: Scientific Software International. Kline, R. (2005). Principles and practice of scructural equation modelling. New York: Guilford Publications.

Milner, R. (1989). Communication and concurrency. London: Prentice Hall.

Odabaşı, F. (2016, 3 15). Toplumsal etkiler ve teknoloji okuryazarlığı. http://home.anadolu.edu.tr/ fodabasi/doc/ty2.swf . adresinden alınmıştı Özgenç, Ö. (2012). Çalışma yaşamında işbirliği. Ankara: ILO.

P21. (2016, 03 14). http://www.p21.org/storage/documents/P21_arts_map_final.pdf.

Pacific Policy Research Center. (2010). 21st century skills for students and teachers. Honolulu: Kamehameha Schools, Research \& Evaluation Division.

Partnership. (2011). Framework for 21st Century Learning. 01 13, 2017 tarihinde http://www.p21.org/. adresinden alındı

Partnership for 21st Century Skills. (2008). 21 st. century skills, education and competitiveness. Tucson, AZ: Author.

RTÜK. (2016). 03 03, 2016 tarihinde http://www.medyaokuryazarligi.org.tr. adresinden alındı

Schater, M. (2000). When Accountability Fails: A Framework for Diagnosis and Action Policy Brief. Canada: Institue on Governance. 
Schumacker, R. L. (2004). Abeginner's guide to structural equation modeling. Hillsdale,NJ: Erlbaum.

Shaw, A. (2004). About the 21st century and education.21st century school-professional staff development and curriculum design. Ocak 2016 tarihinde 21st century schools: http://www.21stcenturyschools.com/index.html adresinden alındı

Silva, E. (2008). Measuring Skills For The 21st Century. Washington DC: Education Sector Reports.

Sungur, N. (1997). Yaratıcı düşünce. İstanbul: Evrim Yayınları.

Sümer, N. (2000). Yapısal eşitlik modelleri. Türk Psikoloji Yazıları, 3(6), 49-74.

Şimşek, Ö. (2007). Yapısal eşitlik modellemesine giriş: Temel ilkeler ve LISREL uygulamaları. Ankara: Ekinoks.

Tabachnick, B. \&. (2001). Using Multivariate Statistics. USA: Allyn\& Bacon.

Torrance, E., \& Ball, O. E. (1974). Torrance tests of creative thinking. Benselville: Norm Technical Manual Scholastic Testing Servize, Inc.

TTKB. (2016, 03 15). http://www.medyaokuryazarligi.org.tr/nedir.html. adresinden alınmıştır

Türk Dil Kurumu Sözlüğü. (2015).

Webster. (2016). http://www.merriam-webster.com/. 